\title{
Towards a Framework for CSCL Research
}

\author{
Citation for published version (APA):
}

Kirschner, P. A., \& Erkens, G. (2013). Towards a Framework for CSCL Research. Educational Psychologist, 48(1), 1-8. https://doi.org/10.1080/00461520.2012.750227

\section{DOI:}

10.1080/00461520.2012.750227

Document status and date:

Published: 18/01/2013

Document Version:

Peer reviewed version

Please check the document version of this publication:

- A submitted manuscript is the version of the article upon submission and before peer-review. There can be important differences between the submitted version and the official published version of record. People interested in the research are advised to contact the author for the final version of the publication, or visit the DOI to the publisher's website.

- The final author version and the galley proof are versions of the publication after peer review.

- The final published version features the final layout of the paper including the volume, issue and page numbers.

Link to publication

\section{General rights}

Copyright and moral rights for the publications made accessible in the public portal are retained by the authors and/or other copyright owners and it is a condition of accessing publications that users recognise and abide by the legal requirements associated with these rights.

- Users may download and print one copy of any publication from the public portal for the purpose of private study or research.

- You may not further distribute the material or use it for any profit-making activity or commercial gain

- You may freely distribute the URL identifying the publication in the public portal.

If the publication is distributed under the terms of Article 25fa of the Dutch Copyright Act, indicated by the "Taverne" license above, please follow below link for the End User Agreement:

https://www.ou.nl/taverne-agreement

Take down policy

If you believe that this document breaches copyright please contact us at:

pure-support@ou.nl

providing details and we will investigate your claim.

Downloaded from https://research.ou.nl/ on date: 26 Apr. 2023 
Towards a Framework for CSCL Research

\author{
Paul A. Kirschner ${ }^{1}$ \& Gijsbert Erkens ${ }^{2}$ \\ ${ }^{1}$ Centre for Learning Sciences and Technologies, Open University of the Netherlands \\ ${ }^{2}$ Department of Pedagogical and Educational Sciences, Utrecht University
}

Corresponding author: Prof. dr. Paul A. Kirschner, Centre for Learning Sciences and Technologies (CELSTEC). Open University of the Netherlands, Valkenburgerweg 177, 6419AT Heerlen, The Netherlands. Email: paul.kirschner@ou.nl 


\begin{abstract}
Although collaborative learning, often supported by computer networks (widely called computer supported collaborative learning, or CSCL) is currently being implemented at all levels of education, it has not always proven to be the wonder-tool that educators envisioned and has often not lived up to the high expectations that educators had for it. In this introduction to the special issue on computer supported collaborative learning (CSCL), a framework for research on CSCL is presented. This framework is presented in the form of a 3 X 3 X 3 cube, with the dimensions Level of Learning (cognitive, social, and motivational), Unit of Learning (individual, group/team, and community) and Pedagogical measures (interactive, representational, and guiding). Based on this framework, the different contributions are discussed, and the empty cells - which should form the basis for further theoretical research - become evident.
\end{abstract}




\section{Towards a Framework for CSCL Research}

Collaborative learning, often supported by computer networks (widely called computer supported collaborative learning, or CSCL), is currently being implemented at all levels of education. One major reason for this is that many educators are convinced that CSCL environments permit them to implement current insights in teaching and learning that rely on working, thinking and creating knowledge together. These insights make use of pedagogical techniques such as inquiry, critical discourse, and critical thinking, which are expected to stimulate and allow learners to learn more deeply and meaningfully. A second reason for implementing CSCL is that it (a) enables learners and instructors to be geographically dispersed and, thus, eliminates the need for learners and instructors to be colocated for meetings and discussions and (b) allows learners to engage in learning at any time, thus also eliminating the need for co-presence (Kreijns, Kirschner, \& Jochems, 2003). This Special Issue on CSCL addresses critical issues related to making CSCL effective as a means of learning.

Unfortunately, CSCL has not always proven to be the wonder-tool that educators envisioned and has often not lived up to the high expectations that educators had for it and beneficial effects on learning have not always been found (Lou, Abrami, \& d'Apollonia, 2001). It has become clear that simply placing learners in a group and assigning them a task does not guarantee that they will work together (Hughes \& Hewson, 1998), coordinate their activities (Erkens, Prangsma, \& Jaspers, 2006), engage in effective collaborative learning processes (Hallet \& Cummings, 1997), participate in argumentative discussions (Weinberger, \& Fischer, 2006), or lead to positive learning outcomes (Beers, 2005; De Westelinck, Valcke, De Craene, \& Kirschner, 2005; Mäkitalo, Weinberger, Häkkinen, Järvelä, \& Fischer, 2005; Van Bruggen, Kirschner, \& Jochems, 2002; Van Drie, Van Boxtel, Jaspers, \& Kanselaar, 2005). 
There are a number of reasons for this shortfall, many of which are discussed in the different articles in this Special Issue, together with measures to counteract the problems. Fischer, Kollar, Stegmann and Wecker (this issue), for example, discuss how using scripts at different levels can effectively scaffold the interaction in CSCL; Fransen, Weinberger and Kirschner (this issue) discuss how CSCL team development can be stimulated such that team members can learn effectively. It is, not the intention of this introductory article to discuss the different measures and approaches. What this article does try to do is present some of the more general problems with and aspects of CSCL and then present a framework for further research on CSCL.

Basic to all of this is that a team more is than simply a group of people who-with the aid of physical and/or virtual artifacts - try to work together. Many of the assumptions that go hand-in-hand with effective and efficient CSCL and that underlie the successful solution of a problem and/or construction of knowledge are based upon two premises.

The first premise is that learners in CSCL function as teams. This means that learners, for example, trust each other in the team to do what has been agreed upon, know each other's weak and strong points and make use of them, share similar norms for working and goals of the teamwork, and so on. As Fransen, Weinberger, and Kirschner (this issue) show, learning teams typically do not begin with these characteristics, and developing as a team takes time. A first problem encountered in CSCL, thus, is that when learners are often "thrown together" in groups for short periods of time to carry out a task, design a project, or solve a problem, they are expected to work as a team. They often are given neither the time nor the conditions that are needed to allow groups to move from a group of students "thrown together" to a functioning team that learns.

The second premise is that learners in CSCL experience working in teams as positive in that they feel motivated that the extra time and effort that need to be invested to work 
together pays off. This means that the costs for communication with others and coordination of activities are compensated by the returns in terms of ease of and ability to learn.

F. Kirschner, Kirschner and Paas (2009) refer to this as the transactional costs involved in collaboration. Collaborative learning will only occur/work when the costs in terms of invested time and effort are exceeded by the benefits in terms of effectiveness and efficiency of learning. If the perceived or actual costs are greater than the returns/benefit, then collaboration will not occur. Thus, in addition to team forming, motivation is an important pre-condition for collaborative learning.

\section{Elements of CSCL}

Computer Supported Collaborative Learning is about learners learning together with the support of computers connected to each other via a computer network (e.g., a wide or local area network, internet, et cetera). A better, though less sexy, name would be Learning Collaboratively Supported by Computers in Networks (LCSCN). This means that CSCL should be viewed as a triptych that begins with learning (and thus needs a pedagogy), that occurs with others (and thus needs to be social) and that takes place through / is facilitated by computers (and thus makes use of technology). The next three paragraphs discuss these elements.

The pedagogical element refers to the learning part of the CSCL environment. The pedagogical measures in the collaborative learning environment are taken to facilitate the learning process by the students while working together on a collaborative learning task. These pedagogical measures can be embedded in the computer environment in the form of specific tools that support the students to fulfill the collaborative task. Three examples of such tools are: (a) an interactive tool that requires students to clarify or explicate their contributions, such as a negotiation tool (Kirschner, Beers, Gijselaers, \& Boshuizen, 2008); (b) epistemic prompts that require students to think about their own contributions and those of 
other team members, such as sentence openers or question stems (Scardamalia \& Bereiter, 1996) or note starters (Nussbaum, Hartley, Sinatra, Reynolds, \& Bendixen, 2002); and (c) representations that support students through the learning and/or task-execution process (e.g., Suthers, Hundhausen, \& Girardeau, 2003; Slof, Erkens, Kirschner, \& Jaspers, 2010; Slof, Erkens, Kirschner, Jaspers, \& Janssen, 2010). The pedagogical measures can also be in the form of a script that guides students through important phases or aspects of the task (Weinberger, Ertl, Fischer, \& Mandl, 2005). Finally, the pedagogical measure can take the form of specific supports by the instructor to guide students, such as providing them with process worksheets to guide the process or providing just-in-time support for them when a specific problem arises (Van Merriënboer \& Kirschner, 2012).

Tools, scripts, and teacher (or computer) scaffolding in the pedagogical component focus on supporting the cognitive and meta-cognitive aspects of task fulfillment. Cognitive support focuses on executing the task itself, whereas metacognitive support focuses on the task strategy and regulation (i.e., the planning, monitoring and evaluation of task execution). In other words, the pedagogical component refers to the learning goals of the task. However, in collaborative learning the learning goals may be aimed at the individual student, at the collaborating group as a whole (learning team), or even to the community (class or school) to which the collaborating groups belong. Depending on the unit that the learning goals are aimed at, the support that is offered can be different.

The social element of CSCL refers to the collaborative and/or interactive part of CSCL. In CSCL, it is assumed that learning is facilitated in a collaborative learning situation; that is, when students in groups work together constructively on a learning task. Essential to the collaboration is that students work together on a common product with shared responsibility (see Fransen, Weinberger, \& Kirschner, this issue). For collaboration to be effective, students must explicate their thoughts, actively participate, discuss and negotiate 
their views with the other students in their team, coordinate and regulate their actions between them, and share responsibility for both the learning process and the common product. Furthermore, they have to form a real group and evolve in an effective learning and working team. Examples of tools that can aid in this process are (1) social / group awareness tools (Kirschner \& Kreijns, 2004) and (2) tools that prompt team members to reflect upon their actions and provide feedback to other group members (Phielix, Prins, \& Kirschner, 2010; Phielix, Prins, Kirschner, Erkens, \& Jaspers, 2011). In collaborating, not only cognitive and metacognitive aspects of subject matter content play an important role, but also the social and meta-social aspects of collaboration. The social aspects refer to the social and communicational knowledge and skills that students use to collaborate effectively with each other. These knowledge and skills determine how students explain to each other, give arguments without arguing, solve conflicts when they occur, communicate in a clear way, regulate each other's participation and activities, divide tasks between each other in a fair way, and respect each other's contribution. Social support focuses on the collaboration directly, while meta-social support is directed toward participants' awareness of social aspects of collaboration. Meta-social support is accomplished primarily by reflection prompts whereby the team members are stimulated in reflecting on the effects of their actions and those of others on the social functioning of the team. Both social and meta-social aspects relate to the motivational and affective aspects of collaborative learning. Motivation as a precondition for collaborative learning has to be maintained, and so must a positive feeling for the learning situation. Social support or teacher support may help to overcome and regulate problems in motivation and affect to promote learning and collaboration (Järvelä \& Hadwin, this issue; Puntembekar \& Hubscher, 2005; Rienties, Tempelaar, Van den Bossche, Gijselaers, \& Segers, 2009). 
The technological element refers to the computer-supported part of CSCL and thus the potentials and limitations that computer-based support gives to facilitate the collaborative cognitive and social learning processes. Pedagogical and social support by means of tools, scripts, and scaffolding is dependent on the functionalities and restrictions of the technological possibilities of the CSCL environment. A chat tool, for example, offers independency of location as it allows for the possibility for team members to communicate with each other without being in the same spot. However, because it is text based, it does not allow for non-verbal, visual communication as face-to-face communication does (whether in the same place or through tools such as Skype). And because it is a real-time application, it can be a problem when carried out in a non-synchronous team. On the other hand, a tool such as Skype, which allows team members to see each other during interaction, presents problems when network speed and/or bandwidth are limited.

Most CSCL environments offer a combination of communication and (cognitive and/or social) productivity tools. Communication tools allow students to communicate via the network with each other during collaboration. This can be synchronous or asynchronous, text, audio-, and/or video-based, and within groups, between groups or within communities. Productivity tools allow completion of the collaboration task. For example, a shared text processor is a cognitive productivity tool that helps students organize their information in a common written product. A participation tool such as the one used by Janssen, Erkens, Kanselaar, and Jaspers (2007) is a social productivity tool that visually represents the degree and type of contribution of the participants in a group. A cognitive scripting productivity tool may enforce the students to follow specified problem-solving steps to solve the collaborative task at hand (Slof, Erkens, Kirschner, \& Jaspers, 2010), while a social scripting tool can provide learners with scenarios for social interaction which, for example can help transform a group of individuals into a collaborating team (Zahn, Krauskopf, Hesse, \& Pea, 2012). The 
degree in which these tools are individual or shared (i.e., are accessible and workable for group or community members) is an important question of interactivity in this respect. With new technological developments, like web 2.0, mobile technology, global positioning systems, and embedded technologies, new possibilities for cognitive, social and motivational support for collaborative learning become possible.

\section{A 3 X 3 X 3 Theoretical Framework for CSCL}

Based on the distinctions presented above, we propose a 3 X 3 X 3 cube as a theoretical framework for conceptualizing CSCL research and development, including the articles in this special issue. The three dimensions of the cube are:

- $\quad$ Level of Learning

- $\quad$ Cognitive (task execution \& regulation)

- $\quad$ Social (group/team forming \& coordination)

- $\quad$ Motivational (coping \& regulation)

- $\quad$ Unit of Learning

- Individual

- $\quad$ Group/team

- $\quad$ Community

- $\quad$ Pedagogical measures

- Interactive (argumentation, negotiation, communication, explication)

- $\quad$ Representational (organization, structuring, awareness)

- $\quad$ Guiding (scripting, scaffolding, instruction)

The level of learning describes whether the aims of learning in a theory or research are mainly directed at (1) cognitive (task and/or subject matter oriented) or metacognitive learning goals (knowledge of oneself and in a collaborative learning situation about others as cognitive processors), (2) social (team/group collaboration oriented) or meta-social learning 
goals (self- and group efficacy, empowerment; Francescato, Mebane, Porcelli, Attanasio, \& Pulino, 2007; Francescato, Mebane, Solimeno, Sorace, \& Tomai, 2006) or (3) motivational or affective learning goals (attitudes, values, predispositions, opinions, beliefs towards what is to be learned and others within a group or team), or at a combination of these three learning levels. The results that are claimed for (computer supported) collaborative learning may be distinguished at these same levels: domain knowledge and (meta)cognitive skills, interpersonal and collaboration skills and motivation (see for example the review of Johnson \& Johnson, 1999). The pedagogical measures by tools, scripts or teacher support in CSCL may likewise be categorized as being aimed at cognitive, social or motivational learning goals.

The unit of learning refers to the agent that is supposed to learn from CSCL. Traditionally, from a point of view of cognitivism, collaborative learning is aimed at individual learning gains of collaborating participants. By working in a team, through argumentation and discussion with others, the learner will reach a deeper level of learning (Ludvigsen \& Morch, 2010). From socio-constructivist or socio-cultural points of view larger entities like groups or communities will learn from collaborative learning situations as a whole, regardless of individual learning gains (Stahl, 2006). For example, to support nonprofit community-based volunteer organizations in their struggle to use information technology in a professional way, Carroll and Farooq (2007) propose patterns as standard solution schemata for recurrent problems. To counter the knowledge loss from volunteer turnover in a food bank organization with a small permanent staff and many volunteers, they developed a Scaffolded Documentation pattern helping staff and volunteer community members sustain and document organizational knowledge.

The third dimension refers to the pedagogical measures in computer tools and teacher support that have been taken in the design of collaborative learning environment to facilitate 
reaching the learning goals. Here, we distinguish among three types. Interactive pedagogical measures are aimed the facilitation of the communicative and interactive processes between the collaborating students to support discussion, information sharing, and deliberation among them. Interactive pedagogical measures vary from asynchronous discussion forums to chat facilities, from product sharing (groupware) to meeting schedulers. Representational pedagogical measures refer to the pedagogical measures that either structure or help students to structure and organize information or knowledge at the cognitive, social or motivational level. Representational pedagogical measures vary from argumentation or concept maps to participation or social presence tools, from tools that allow voting on debatable issues (showing everybody's preferences) to the use of smiley faces to represent participants' mood and motivation. Representational pedagogical measures are meant to make students aware of elements and interrelations between them at task, team, or affect level. Finally, guiding pedagogical measures are meant to guide and direct collaborating students through the learning and collaboration process. They give direction and help the students to determine the next step in the process. Guiding pedagogical measures vary from scripts for problem solving to collaboration time lines (indicating when to divide tasks and when to integrate them), from help on demand facilities to teacher's scaffolds.

Of course, this 3 X 3 X 3 theoretical framework for CSCL is not exhaustive and has its limitations. Nevertheless, in this introduction for this special issue, it helps frame the five contributions in relation to each other and within the field of CSCL. The overview will, hopefully, give the readers insights into new developments in the field of CSCL, and in this issue what is happening in Europe in particular. However, not all cells in the cube will be filled, which leads to new questions for future research.

\section{Positioning the Contributions within the Framework}


Fransen, Weinberger, \& Kirschner: Team effectiveness and team development in CSCL

Level: $\quad$ cognitive \& social

Unit: $\quad$ group/team

Pedagogical measure: $\quad$ guiding

In this article, the authors look to the field of Computer Supported Collaborative Work (CSCW) to determine which mechanisms and components of CSCW contribute to the development of effective work teams and ask whether similar mechanisms and components could be viewed as essential for developing and sustaining effective learning teams in CSCL. Effectiveness is defined by the authors in terms of both task fulfillment (i.e., effectiveness at the cognitive level) and team functioning (i.e., effectiveness at the social level). Supporting and coordinating mechanisms are needed for effective learning teams to develop from randomly assigned groups of learners to well functioning teams. These mechanisms are the development of both mutual trust between members on task and team levels and shared mental models about task and team goals, as well as the possibility of closed loop communication in which concise information about task or team functioning can exchanged, acknowledged and confirmed. Not all factors that are relevant for effective CSCW-teams seem relevant for effective CSCL-teams. Effective learning team behavior seems to be dependent upon a number of behavioral components, namely mutual performance monitoring (keeping track of each other's task activities), back-up behavior (backing up other member's failures) and adaptability (ability to adjust task or team strategies). These behavioral components refer to coordinating and regulating activities and thus reflect metacognitive and meta-social strategies. The authors relate these mechanisms and behavioral components to different phases in team development. Team development is not only dependent on internal dynamics like the transition to another task phase or developing more mutual trust, but can also be triggered by external changes of circumstances, like changing deadlines or the sudden 
absence of a member, to which a team has to adapt. The authors discuss scripting as the guiding pedagogical measure to facilitate and support teamwork and team development. Such scripts specify, sequence, and distribute roles and activities across a team of learners and, thus, guide them to engage in transactive interactions. Furthermore, such collaboration scripts can help students monitor their mutual performance and, through the specification of roles, to coordinate the activities of team members in effective teams.

Järvelä, \& Hadwin: New frontiers: Regulating learning in CSCL

Level: $\quad$ cognitive, social \& motivational

Unit: $\quad$ individual, group/team

Pedagogical measure: $\quad$ representational, guiding

Järvelä, \& Hadwin focus in their article on the regulating processes in collaborative learning in CSCL, the types of regulation for successful collaboration and the way regulation can be supported by computer tools. In contrast to the question of how students co-construct knowledge, they ask themselves how students during collaboration regulate their task goals and activities together (in planning, monitoring and evaluating), regulate and coordinate their collaboration (in roles and task division) and regulate their own and other's level of motivation and emotions. In short, regulation refers to the meta-cognitive, meta-social and meta-motivational activities that students employ to obtain and maintain a shared approach and coordinated collaboration on a learning task. According to the authors, regulatory behavior is intentional, goal-directed, metacognitive, and situated in the social system. They distinguish three types of regulated learning that contribute to collaborative success: selfregulation (monitoring own, personal goals/standards with regard to the group task), coregulation (monitoring goals/standards of the other members in the group) and shared regulation (monitoring of shared goals/standards by the group as a collective). The skills for 
self-regulation, co-regulation and shared regulation of students in collaborative learning are not well developed and could be supported and promoted by pedagogical measures, mainly computer tools in CSCL. Several examples of promising tools are described. In particularly, the authors discuss guiding tools that structure the collaboration through role assignments or through prescribing scripts and representational tools (named mirroring tools by the authors) that collect and reflect data back about individual and collective actions and engagement. An example of the latter, is the 'Adaptive instrument for Regulation of Emotions' (AIRE), codeveloped by one of the authors, in which students are asked to identify socio-emotional challenges during collaboration and to reflect on how emotional experiences affect collaboration. The responses are used to generate feedback about each other's perspectives and helped the group members to become aware and regulate own, other's, and shared interpretations of the collaboration.

Janssen, \& Bodemer: Coordinated Computer-Supported Collaborative Learning: Awareness and Awareness Tools

Level: cognitive \& social

Unit: $\quad$ individual \& group/team

Pedagogical measure: $\quad$ representational

In the article the authors investigate the concept of awareness in CSCL. Contrasted to spatial awareness as being used in CSCW (who is where and online?), the concept of awareness in CSCL can be distinguished in cognitive group awareness (information about other member's knowledge and task related expertise) and social group awareness (social presence, information about other member's participation and contributions to the collaboration process). From an extensive review of research on awareness in CSCL, the authors show that both cognitive and social awareness affect the coordination of collaborative 
activities at the task-related, cognitive level (content space) and at the collaboration-related, social level (relational space). So being aware of each other's knowledge and expertise not only helps to discuss and to come to a shared understanding of task relevant information, but can also help group members, through social comparison, to set higher standards for themselves and to function better as a group. Whereas social comparison theory can explain the effect of social group awareness on coordinating collaboration, cognitive load theory may explain why cognitive group awareness reduces the effort to coordinate task activities and may even encourage germane learning processes like giving elaborate explanations.

Awareness tools in CSCL are representational by nature: they present or visualize not directly observable information about the knowledge/expertise of group members or about their social participation or presence; at the individual or at the group level; in a quantitative or qualitative manner; in a detailed or in a more global manner. Various examples and variations of cognitive and social awareness tools found in literature are discussed along these dimensions.

\section{Fischer, Kollar, Stegmann, \& Wecker: Towards a script theory of guidance in Computer}

\section{Supported Collaborative Learning.}

Level:

cognitive \& social

Unit: individual

Pedagogical measure: $\quad$ guiding

In this article the authors present an outline of a script theory of guidance for CSCL. In the theory, internal collaboration scripts and external collaboration scripts are the main pedagogical measures. Internal collaboration scripts develop through internalization of collaborative learning experiences and guide the learner in new collaboration situations. Participating in a new collaboration practice the learners activities are guided by a (re)configuration of existing internal collaboration script components consisting of play, 
scenes, roles, and scriplets (internal script guidance principle). This (re)configuration is influenced by the learner's goals and perception of the situation (configuration principle). Through repeated application of a specific configuration of script components over similar situations, higher level components (play, scenes and roles) are developed (induction principle). If the learner's configuration of internal script components is not successful in a CSCL practice, the configuration will be modified (reconfiguration principle). If the collaboration situation asks for transactive discourse, where learners build on each other's contributions, more knowledge will be learned (transactivity principle). External collaboration scripts offered by computer tools or teacher support may facilitate specific internal script components or may inhibit specific dysfunctional internal script components to be activated (external script guidance principle). Optimal external scripts refer to scaffolding at the appropriate level, stating that external scripts should be aimed at higher level internal script components than the learner already possesses (optimal external script guidance principle). These seven principles of the script guidance theory are illustrated by the authors with examples from a range of different studies, with scripts at the cognitive level as well as on the social level of collaboration. In its unit of learning, the theory is aimed at the internal collaboration scripts of the individual learner in the collaborative group. The pedagogical measure that is propagated is guiding: scaffolding and supporting the learners with external scripts through (parts of) the collaboration process. The main challenge, according to the authors, will be to dynamically adapt external scripts to requirements of the learners and of the situation.

\section{Concluding remarks}

In this introduction to the special issue on computer supported collaborative learning (CSCL) we have presented a framework for research on CSCL to discuss the five contributions as well as the most prominent areas of research that are still needed. 
As for the level of learning, it is clear that there is a lot of attention to the social level of collaborative learning in CSCL in these five articles. The collaboration process itself, group/team forming, the participation of group members, the social relations between them and the social climate are seen as important factors in collaborative learning. Furthermore, the metacognitive aspects of collaborative activities, that is regulating behavior (also by internal scripts) and awareness of the collaborative situation at the cognitive and social level, are the focus of much research.

All research is aimed at the learning of individuals and some at learning of groups as a whole; none of the articles discuss the learning and context of greater units like the classes or schools of which the collaborating groups are part. Examples of research questions that could be asked at the community level include questions about the awareness of competencies among groups in a class, the learning of collaboration guiding expertise of teachers in classes, and the effects of a social climate in a school for the implementation of CSCL.

As for the pedagogical measures, the authors have directed the most attention to support with computer tools of a representational (awareness) and of a guiding (scripts) nature. Supporting the interaction process itself (argumentation, negotiation, elaboration, explanation) with tools has been the focus of much earlier research in CSCL (Noroozi, Weinberger, Biemans, Mulder, \& Chizari, 2012), but is not represented in this review. Besides support from computer tools, the role of the teacher in supporting or guiding in CSCL could be a focus for further research.

Finally, is also important to look at more purely social aspects of CSCL. In an upcoming issue of Educational Psychologist, Kreijns, Kirschner and Vermeulen (in press) make a plea for more attention to the social level of learning in CSCL. In that article, they propose a theoretical framework in which sociability, social presence and social space are the key elements for effective social interaction to occur in CSCL. Sociability is afforded by 
characteristics of the technology and the social system or the group itself, and determines the social presence which is the degree to which learners in a CSCL environment experience each other as real during collaboration. The social space refers to the social climate, norms and values, cohesiveness, and trust that are developed during social interaction in a group. A sound social space will not only sustain an open, critical learning environment but supporting social interaction between the members in the group also has motivational effects promoting positive feelings of well-being and satisfaction according to this framework.

But to paraphrase Jeremy Roschelle (this issue) in his critical closing article to this special issue: This special issue brings the field quite a bit further, but we aren't there yet! He posits that we not only need a comprehensive theory of CSCL, but we also need to look at how CSCL can and possibly is changing our theories of learning more broadly both with respect to small-group learning and learning in communities. He also notes that there may be important differences in the use and effects of CSCL in different domains and that this issue is (and we as editors of the issue must say this was a conscious choice) domain-neutral. Finally, he poses that collection does not go deep in theorizing technology; what he calls the "CS" half of CSCL by not discussing and interpreting the current affordances of the new infrastructure being deployed in schools. All of these are valid criticisms but also worthy of future special issues in themselves. As such, a challenge to readers of this special issue to roll up their sleeves and get their hands and arms dirty. 


\section{References}

Beers, P. J. (2005). Negotiating common ground: Tools for multidisciplinary teams. Unpublished doctoral dissertation, Open University of The Netherlands, Heerlen, The Netherlands.

Carroll, J. M, \& Farooq, U. (2007). Patterns as a paradigm for theory in community-based learning. International Journal of Computer-Supported Collaborative Learning, 2, 4163.

De Westelinck, K., Valcke, M., De Craene, B., \& Kirschner, P. A. (2005). Multimedia learning in social sciences: Limitations of external graphical representations. Computers in Human Behavior, 21, 555-573.

Erkens, G., Prangsma, M., \& Jaspers, J. (2006). Planning and coordinating activities in collaborative learning. In A. M. O’Donnell, C. E. Hmelo-Silver, \& G. Erkens (Eds.), Collaborative learning, reasoning, and technology (pp. 233-263). Mahwah, NJ: Lawrence Erlbaum Associates, Publishers.

Francescato, D., Mebane, M., Porcelli, R., Attanasio, C., \& Pulino, M. (2007). Developing professional skills and social capital through computer supported collaborative learning in university contexts. International Journal of Human-Computer Studies, 65(2), $140-152$.

Francescato, D., Mebane, M., Solimeno, A., Sorace, R., \& Tomai, M. (2006). Enhancing professional skills, meta-social competencies and social capital through online collaborative learning. Proceedings of the 5th WSEAS International Conference on Applied Computer Science, Hangzou, China, April 16-18.

Hallet, K., \& Cummings, J. (1997). The virtual classroom as authentic experience: Collaborative, problem-based learning in a WWW environment. In Proceedings of the 
annual conference on Distance teaching and learning: Competition-connectioncollaboration (pp. 103-107). Madison, WI: University of Wisconson-Madison.

Hughes, C., \& Hewson, L. (1998). Online interactions: Developing a neglected aspect of the virtual classroom. Educational Technology, 38, 48-55.

Johnson, D. W., \& Johnson, R. T. (1999). Learning together and alone: cooperative, competitive, and individualistic learning ( $5^{\text {th }}$ Ed.). Boston, MA: Allyn \& Bacon.

Kirschner, F., Paas, F., \& Kirschner, P. A. (2009). A cognitive-load approach to collaborative learning: United brains for complex tasks. Educational Psychology Review, 21, 31-42.

Kirschner, P. A., \& Kreijns, K. (2004). Designing sociable CSCL environments: Applying interaction design principles. In P. Dillenbourg (Series Ed.) \& J. W. Strijbos, P. A. Kirschner \& R. L. Martens (Vol. Eds.), Computer-supported collaborative learning: Vol 3. What we know about CSCL ... and implementing it in higher education (pp. 241-263). Boston, MA: Kluwer Academic Publishers.

Kirschner, P. A., Beers. P. J., Boshuizen, H. P. A., \& Gijselaers, W. H. (2008). Coercing shared knowledge in collaborative learning environments. Computers in Human Behavior, 24, 403-420.

Kreijns, K., Kirschner, P. A., \& Jochems, W. (2003). Identifying the pitfalls for social interaction in computer-supported collaborative learning environments: A Review of the Research. Computers in Human Behavior, 19, 335-355.

Kreijns, Kirschner, P. A., \& Vermeulen, M. (2013, in press). Social aspects of CSCL environments: A research framework. Educational Psychologist, 48(3).

Lou, Y., Abrami, P. C., \& d'Apollonia, S. (2001). Small group and individual learning with technology: A meta-analysis. Review of Educational Research, 71, 449-521.

Ludvigsen, S., and Mørch, A. (2010). Computer-supported collaborative learning: Basic concepts, multiple perspectives, and emerging trends. In B. McGaw, P. Peterson \& E. 
Baker (Eds.), The International Encyclopedia of Education 3rd Edition, Volume 5 (pp. 290-296). Oxford, UK: Elsevier.

Mäkitalo, K., Weinberger, A., Häkkinen, P., Järvelä, S., \& Fischer, F. (2005). Epistemic cooperation scripts in online learning environments: Fostering learning by reducing uncertainty in discourse? Computers in Human Behavior, 21, 603-622.

Noroozi, O., Weinberger, A., Biemans, H. J. A., Mulder, M., \& Chizari, M. (2012). Argumentation-based computer-supported collaborative learning (ABCSCL). A systematic review and synthesis of fifteen years of research. Educational Research Review, 7(2), 79-106.

Nussbaum, E. M., Hartley, K., Sinatra, G. M., Reynolds, R. E., \& Bendixen, L. D. (2002). Enhancing the quality of online discussions. Paper presented at the Annual meeting of the American Educational Research Association, New Orleans, LA.

Phielix, C., Prins, F. J., Kirschner, P. A. (2010). Awareness of group performance in a CSCL environment: Effects of peer feedback and reflection. Computers in Human Behavior, $26,151-161$

Phielix, C., Prins, F. J., Kirschner, P. A., Erkens, G., \& Jaspers, J. (2011). Group awareness of social and cognitive performance in a CSCL environment: Effects of a peer feedback and reflection tool. Computers in Human Behavior, 27, 1087-1102.

Puntambekar, S., \& Hubscher, R. (2005). Tools for Scaffolding students in a complex learning environment: What have we gained and what have we missed? Educational Psychologist, 40, 1-12.

Rienties, B., Tempelaar, D. T., Van den Bossche, P., Gijselaers, W. H., \& Segers, M. (2009). The role of academic motivation in Computer-Supported Collaborative Learning. Computers in Human Behavior, 25, 1195-1206. 
Scardamalia, M., \& Bereiter, C. (1996). Computer support for knowledge-building communities. In T. Koschmann (Ed.), CSCL: Theory and practice of an emerging paradigm (pp. 249-268). Mahwah, NJ: Erlbaum

Slof, B., Erkens, G., Kirschner, P. A., \& Jaspers, J. (2010). Design and effects of a representational scripting tool on group performance. Educational Technology Research and Development, 58, 589-608.

Slof, B., Erkens, G., Kirschner, P. A., Jaspers, J., \& Janssen, J. (2010). Guiding students’ online complex learning-task behavior through representational scripting. Computer in Human Behavior, 26, 927-939.

Stahl, G. (2006). Group cognition: Computer support for building collaborative knowledge. Cambridge, MA: MIT Press.

Suthers, D., Hundhausen, C., \& Girardeau, L. (2003). Comparing the roles of representations in face-to-face and online computer supported collaborative learning. Computers \& Education, 41, 335-351.

Van Bruggen, J., Kirschner, P. A., \& Jochems, W. (2002). External representation of argumentation in CSCL and the management of cognitive load. Learning and Instruction, 12, 121-138.

Van Drie, J., Van Boxtel, C. A. M., Jaspers, J., \& Kanselaar, G. (2005). Effects of representational guidance on domain specific reasoning in CSCL. Computers in Human Behavior, 21, 575-602.

Van Merriënboer, J. J. G., \& Kirschner, P. A. (2012). Ten steps to complex learning $\left(2^{\text {nd }}\right.$ edition). New York: Taylor \& Francis.

Weinberger, A., Ertl, B., Fischer, F., \& Mandl, H. (2005). Epistemic and social scripts in computer-supported collaborative learning. Instructional Science, 33(1), 1-30. 
Weinberger, A., \& Fischer, F. (2006). A framework to analyze argumentative knowledge construction in computer supported collaborative learning. Computers \& Education, 46, 71-95.

Zahn, C., Krauskopf, K., Hesse, F. W., \& Pea, R. (2012). How to improve collaborative learning with video tools in the classroom? Social vs. cognitive guidance for student teams. International Journal of Computer-Supported Collaborative Learning, 7, 259284. 